\title{
ARE PACS TRYING TO INFLUENCE POLITICIANS OR VOTERS?
}

\author{
STEVEN D. LEVITT
}

\begin{abstract}
Political Action Committees (PACs) can affect public policies in either of two ways: altering legislators' roll-call voting behavior, or influencing election outcomes. This paper develops a dynamic model demonstrating that the relative importance of the election-influencing channel is easily underestimated. A one-time contribution to a candidate who supports the PAC's position that alters an election outcome yields benefits to the PAC as long as that candidate holds office. In contrast, roll-call vote buying is likely to operate on a quid-pro-quo basis, limiting the PAC's return on investment. Empirical tests based on the theoretical model suggest that PACs value the election-influencing aspect of contributions at least as much as the roll-call vote-buying channel.
\end{abstract}

CAmpaign contributions by Political Action Committees (PACs) have increased dramatically in the last twenty years. Donations made by PACs to House races grew from $\$ 36$ million to $\$ 120$ million (in constant 1992 dollars) between 1974 and 1992, an increase of over 200\% in real terms. PACs now account for over one-third of all campaign contributions in House races, and one-fourth of contributions to Senate candidates.

In response to the increasing importance of PACs, a great deal of analysis has been devoted to understanding PAC behavior. There are two primary rationales for PAC donations. First, PACs may hope to affect the course of legislation either by "buying votes" in Congress [e.g., Snyder (1990)], or by altering legislation at the committee stage [Hall and Wayman (1989)]. A second possible goal of PAC support is to influence election outcomes, either by attracting voters directly via candidate endorsement, or indirectly through campaign contributions that the candidate transforms into votes [Austen-Smith (1987); Baron (1989)].

In deciding how to allocate campaign contributions across candidates, PACs, need to take into account three (sometimes contradictory) considerations. If the PAC is attempting to influence legislators' votes, then the PAC wants to contribute to winning candidates, typically incumbents, since losing candidates cannot repay favors to the PAC. PACs also want to give to candidates who are on the margin with respect to the PAC's issues. Legislators who staunchly support or oppose the PAC's position are less likely to alter their position in response to campaign contributions than are marginal congressmen. Finally, to the extent that PACs are attempting to influence election outcomes, they want to concentrate contributions on staunch supporters. 
While awareness of each of those roles of PACs is widespread [Sabato (1985), Clawson (1992), Sorauf (1992)], empirical testing has focused primarily on the roll-call vote buying aspect of PAC giving [e.g., Snyder (1990), Stratmann (1992)]. Three empirical predictions emerge from vote-buying models, only the first two of which are well supported in the data. The first prediction is that PAC contributions should be an increasing function of a candidate's likelihood of victory since a losing candidate cannot deliver on his or her end of the promise. A second prediction is that PAC donations should be an increasing function of an elected official's influence in Congress. Indeed, members of key committees such as Ways and Means, receive greater contributions, especially when tax reform is under debate (Birnbaum and Murray, 1987). A third prediction of vote-buying models is that PAC donations, ceteris paribus, should flow to elected officials who are on the margin with respect to the PAC's cause, not to staunch supporters who will cast their vote with the PAC anyway. This prediction is at odds with the data; PACs overwhelmingly give to strong supporters [Gopoian (1984), Poole et al. (1987), Grier and Munger (1993)]. Stratmann (1992), however, provides evidence that contributions do tend to go to legislators who are on the fence.

The primary rationale for focusing on the roll-call vote buying channel of PAC influence is that it seems likely that PACs have a far greater likelihood of affecting the roll-call voting behavior of elected officials than they have of altering the outcome of popular elections. ${ }^{1}$ This is particularly true given tight federal limits on the per candidate donation allowable to an individual PAC. $^{2}$

In this paper, however, I argue that the relative importance of the electioninfluencing channel is easily underestimated. Even if a PAC has only a small influence on election outcomes, this channel can outweigh the vote-buying channel in importance, especially when the likelihood that the candidate will be re-elected in the future is large. The intuition for this result is as follows. Assume a PAC makes a one-time contribution to a candidate who supports the PAC's positions, and never again contributes. With some small probability, that initial contribution makes the difference in the election outcome. As long as that candidate remains in office, the candidate will cast votes that benefit the PAC, even without any further PAC contributions. Therefore, a one-time PAC

\footnotetext{
${ }^{1}$ Although it must be noted that the evidence concerning the ability of PACs to influence roll-call voting behavior is mixed, at best. While numerous papers document a correlation between PAC contributions and a politician's voting record, those papers that most carefully attempt to identify a causal effect of PAC contributions typically fail to uncover evidence that PACs influence legislative roll-call voting patterns [Chappell (1982), Grenzke (1989), Bronars and Lott (1994)]. One exception to this pattern is the work of Hall and Wayman (1990) who focus on behavior in committees rather than on roll-call votes.

${ }^{2}$ Furthermore, studies of the effects of campaign spending on election outcomes have generally found small effects of incumbent spending [Jacobson $(1980,1985,1990)$ ], and sometimes small effects of both incumbent and challenger spending [Ansolabehere and Snyder (1996), Levitt (1994)]. Recent work has sometimes found larger effects of incumbent spending [Green and Krasno (1988, 1990), Erikson and Palfrey (1993)].
} 
investment in electing a supporter pays dividends far into the future. In contrast, if a PAC is attempting to influence roll-call voting behavior by contributing to marginal supporters, the benefits are likely to accrue on a quid-pro-quo basis. In order to elicit the desired voting pattern from a marginal legislator, the PAC will be required to provide a continuing flow of contributions.

I develop a simple dynamic model of PAC behavior that incorporates both vote-buying and election-influencing roles of PACs. Unlike models that rely solely on vote buying, the expanded model is consistent with the empirical observation that PAC contributions are primarily targeted towards staunch PAC supporters rather than congressmen on the margin. A second insight that emerges from the model is that a PAC's return on investment from the electioninfluencing channel is an increasing function of the likelihood that the candidate will stay in office in the future. Therefore, the larger is the incumbency advantage [Gelman and King (1990), Levitt and Wolfram (1996)], the more attractive are PAC contributions to open-seat candidates. The higher is the retirement rate, the less valuable is the election-influencing channel for PAC contributions.

While the main focus of this paper is theoretical, two simple empirical tests of the model are also presented. First, for extremely safe seats, the likelihood that a PAC contribution affects the election outcome is near zero. ${ }^{3}$ Thus, contributions to such races may provide a rough estimate of the magnitude of the vote-buying channel. Furthermore, under certain conditions spelled out in the model, the total contributions to both candidates in a race for vote-buying purposes is independent of the closeness of the election. If that is true, then differences in total PAC contributions between close and lopsided races provide a measure of the importance of the election-influencing channel. Total PAC contributions in close races are more than twice as great, suggesting an important role for election influencing. Furthermore, as the model predicts, virtually all PAC contributions go to the incumbent in lopsided races. The increase in PAC dollars between close and lopsided races is spread relatively equally between incumbents and challengers. While it is impossible to draw definitive conclusions from this comparison, at a minimum, it suggests the possible importance of the electioninfluencing channel.

The second empirical approach exploits the differential effects of partisan swing on incumbents and challengers of the two parties. Partisan swing toward one party unambiguously make challengers of that party more attractive to PACs through both potential channels, while the reverse holds for challengers of the opposing party. The impact of partisan swing on PAC contributions to incumbents, however, is ambiguous. Swings toward one party lessen the likelihood that incumbents of that party will be involved in close races, reducing the election-influencing motive, but increasing the vote-buying incentives. The

\footnotetext{
${ }^{3}$ Of course, seats in predominantly one-party districts may be safe in general elections, but vulnerable to challengers in the primary. Moreover, contributions today may be given in anticipation of influencing future elections.
} 
opposite holds for incumbents of the other party. Empirically, it is demonstrated that challenger PAC contributions are strongly positively correlated with the electoral fortunes of the party. In contrast, PAC contributions to incumbents are negatively related to partisan swing. These results suggest that PAC contributions, at least on the margin, are designed primarily to influence election outcomes rather than change roll-call voting patterns of elected officials.

The structure of the paper is as follows. Section I develops the assumptions of the formal model, while section II solves the model and presents numerical examples. Section III examines the empirical evidence concerning the relative importance of the vote-buying and election-influencing channels. Section IV offers a brief set of conclusions.

\section{SECTION I: A MODEL OF PAC CONTRIBUTIONS}

Assume that there is a rational, risk neutral, single-issue PAC attempting to determine how to allocate campaign contributions across a range of candidates so as to maximize the amount of legislative support for its cause. For simplicity, let the PAC face a constant marginal cost of raising funds. That assumption simplifies the analysis by making the PAC's decision about whether and how much to contribute to each race independent of all other races; allowing the cost of funds to be variable would not, however, change any of the fundamental conclusions of the model. ${ }^{4}$

The PAC's contribution to a particular candidate is denoted $x$. Solely for simplicity, it is assumed that the PAC either makes no contribution to a candidate, or gives a fixed amount $X$, which may be equal to the maximum legally allowable contribution. ${ }^{5}$ Stated formally, $x \in\{0, X\}$.

Candidates are assumed to respond to the differential in PAC giving between themselves and their opponent. In other words, if the PAC gives an equal donation to competing candidates in the model, it receives no benefit. Consequently, PACs will not give to both candidates in a particular race in this model. This result conforms with real world experience. PACs very rarely contribute to two candidates in the same race unless the candidate receiving the initial contribution is defeated in the primary [Bronars and Lott (1994), McCarty and Rothenberg (1994)].

Let the likelihood that a given candidate $j$ supports the PAC's position on a roll-call vote of interest to the PAC if the PAC does not make a contribution be labeled $V_{j}$ where $V_{j} \in[0,1]$. A contribution of $X$ to candidate $j$ in a given period changes the likelihood of a favorable roll-call vote by $\Delta V_{j}$ in that

\footnotetext{
${ }^{4}$ In order to focus as clearly as possible on the tradeoff between election influencing and roll-call vote buying, the model presented here abstracts from many real-world considerations. The key insights of the model, however, are robust to incorporation of more realistic and complicated modeling assumptions.

${ }^{5}$ If the effect of PAC contributions on both roll-call voting behavior and election outcomes is linear, then the assumption of a constant marginal cost of funds to the PAC leads to a "bang-bang" solution in which the PAC either makes no contribution or the maximum allowable contribution.
} 
period only. ${ }^{6}$ Denote the probability that the incumbent wins the election in the absence of any PAC contributions from the PAC in question as $P{ }^{7} P$ will typically be greater than 0.50 . Further assume that PAC contributions affect the probability of victory, either because of the direct benefit of PAC endorsement, or due to the impact of campaign spending on votes. A PAC donation of $X$ to candidate $j$ increases the likelihood that a candidate is victorious by $\Delta P_{j}$. Thus, the probability of victory for an incumbent $i$ who receives $\mathrm{PAC}$ contribution $X$ is given by $P+\Delta P_{i}$; the probability of victory for a challenger $c$ receiving PAC contribution $X$ is given by $1-P+\Delta P_{c} . \Delta P_{i}$ and $\Delta P_{c}$ can be, but need not be, equal.

In determining the optimal allocation of contributions, the PAC must also take into account the likelihood that the legislator will remain in office in future terms. A contribution that raises the chances of a staunch supporter winning election today is far more valuable if that staunch supporter is likely to remain in office for many terms. For simplicity, it is assumed that the PAC's best estimate of the likelihood of incumbents winning in future periods is the same as the likelihood of their winning in the current period, namely $P{ }^{8}$ The probability of retirement is taken to be an exogenous constant $R$.

An important assumption of the model is that any individual PAC's contribution has only a small effect on a either a legislator's roll-call voting behavior or likelihood of election. Given that maximum contributions per candidate by a particular PAC (\$10,000 per election cycle), it is plausible to think that the amount of influence that can be bought is limited. Similarly, $\$ 10,000$ represents just a few percent of the typical House candidates overall campaign spending and a trivial fraction of the standard Senate race, suggesting that the PAC's impact on the election outcome will be small. The practical benefit of assuming that PAC influence is small is that it implies that the interaction between the PAC's behavior across different election cycles is of second order importance, greatly simplifying the solution of the model. Without this assumption, the solution to the dynamic model becomes quite complicated.

Along the same lines, the solution to the model is greatly facilitated by assuming that the challenger's type (i.e., $V_{c}$ ) in future elections is independent of the incumbent's type (i.e., $\left.V_{i}\right) .^{9}$ This assumption is most plausible for issues that are less salient, so that candidate selection will not hinge on the candidate's

\footnotetext{
${ }^{6}$ The precise mechanism by which this agreement is maintained is left unmodeled. Functionally, the elected official is assumed to play a (possibly degenerate) mixed strategy on each vote, and has the capability of committing to alter the likelihood of voting for the PACs position on a particular vote by $\Delta V_{j}$. The most important feature of this arrangement is that it operates on a quid-pro-quo basis; past contributions have no effect on current voting behavior.

${ }^{7}$ The logic of the model readily extends to open seat elections as well.

${ }^{8}$ It would not be difficult to incorporate shifts in a candidate's likelihood of winning over time due, for instance, to an increasing incumbency advantage; nothing important changes in the model.

${ }^{9}$ To the extent that the challenger is likely to take the opposite stance of the incumbent, the assumption of independent candidate types will overstate the importance of the election-influencing channel. If challengers tend to adopt the incumbent's stance on the PAC's issue, the reverse result holds.
} 
stance on this particular issue. Also, the assumption is more realistic for issues that do not break down along party lines, or for highly partisan districts where winning the primary is a virtual guarantee of winning the general election.

Finally, two notational conventions are adopted. First, it is assumed that elections occur at the end of the period. Thus a PAC contribution in period $t$ influences the election outcome in period $t$. Secondly, without loss of generality, the value to the PAC of having one additional legislator in support of the PAC's position for one period is normalized to equal one.

\section{SECTION II: SOLVING THE MODEL}

The solution to the model consists of identifying the conditions under which the PAC alternatively gives to the incumbent, the challenger, or does not contribute to either candidate. The maximization problem faced by the PAC can be expressed as follows:

$$
\max _{z \in\{n, i, c\}} U_{z}=\sum_{t=1}^{\infty} \delta^{(t-1)} U_{z t}
$$

where $\delta$ is a discount factor, $U_{z t}$ is the PAC's payoff in period $t$, conditional on the contribution strategy $z$ in period 1 , where the possible contribution strategies are do not contribute, contribute to the incumbent, or contribute to the challenger.

The simplest way to approach the PAC's maximization problem is to analyze the PAC's payoffs for alternative contribution strategies on a periodby-period basis. The PAC's payoffs in period 1 for the three contribution strategies are

$U_{n 1}=P^{*} V_{i}+(1-P)^{*} V_{c}$ if no contribution

$U_{i 1}=\left(P+\Delta P_{i}\right) *\left(V_{i}+\Delta V_{i}\right)+\left(1-P-\Delta P_{i}\right) * V_{c}-C$ if give to incumbent

$U_{c 1}=\left(P-\Delta P_{c}\right) * V_{i}+\left(1-P+\Delta P_{c}\right) *\left(V_{c}+\Delta V_{c}\right)-C$ if give to challenger

where, as noted earlier, $P$ is the baseline probability of victory for the incumbent, $V_{i}$ and $V_{c}$ are the roll-call voting profiles of the incumbent and challenger respectively, $\Delta P_{i}, \Delta P_{c}, \Delta V_{i}$, and $\Delta V_{c}$ are the effects of PAC contributions on elections and roll-call votes, and $C$ is the cost to the PAC of raising $X$ dollars.

Rearranging (2), (3), and (4),

$$
\begin{aligned}
U_{i 1}-U_{n 1} & =P \Delta V_{i}+\Delta P_{i}\left(V_{i}-V_{c}\right)+\Delta P_{i} \Delta V_{i}-C \\
U_{c 1}-U_{n 1} & =(1-P) \Delta V_{c}+\Delta P_{c}\left(V_{c}-V_{i}\right)+\Delta P_{c} \Delta V_{c}-C
\end{aligned}
$$

Equation (5) is the difference in utility to the PAC in period 1 between contributing to the incumbent and not contributing. Equation (6) is the 
corresponding differential between giving to the challenger and not giving. The first term in equations (5) and (6) reflects the roll-call vote buying channel, the second term is the election-influencing effect, the third term is a second-order interaction between the two channels, and the final term is the cost of the contribution to the PAC. An important point to note is that the effectiveness of a PAC contribution via the roll-call vote buying channel is proportional to a candidate's likelihood of winning the election. In contrast, the benefit to the PAC from the election-influencing channel is independent of the probability of winning. Thus, if a PAC cared only about influencing elections, it would have no incentive to give disproportionately to incumbents unless incumbents are more skilled at turning dollars into votes.

Equations (5) and (6) do not fully capture the maximization problem of the PAC, of course, since the PAC must consider not only the effect of this period's contribution on this period's outcome, but also the effect of this period's contribution on election outcomes in future periods. Three assumptions made earlier simplify the analysis at this stage. First, PAC contributions are assumed to affect legislator roll-call voting behavior only in the current period. Therefore, in considering future periods, only the possible effect on election outcomes needs be considered. Secondly, because the effect of an individual PAC's contribution is assumed to be small, the effect of future contributions on today's contribution decision is of second order importance. Therefore, one can simply assume that the PAC does not contribute at time $t+1$ without materially affecting the solution to the optimal PAC strategy at period $t$. Finally, the assumption that the roll-call voting behavior of future challengers is drawn randomly greatly simplifies consideration of the PAC's payoff in future periods.

There are three possible outcomes in period 2, conditional on the outcome of the first period election. The winner of the first period election can either retire, seek re-election and lose, or seek re-election and win. Given the assumption that future challengers are drawn randomly, the PAC's first period contribution has no effect on the PAC's expected payoff in the second period if the winner of the first period either retires or is defeated in the second period. Since re-election probabilities and retirement rates are taken to be exogenous, it follows from straightforward algebra that the effect of a first period contribution on second period payoffs to the PAC are captured by

$$
\begin{aligned}
U_{i 2}-U_{n 2} & =\Delta p_{i}[P(1-R)]\left(V_{i}-V_{c}\right) \\
U_{c 2}-U_{n 2} & =\Delta p_{c}[P(1-R)]\left(V_{c}-V_{i}\right)
\end{aligned}
$$

where $\Delta P_{i}$ and $\Delta P_{c}$ refer to the effects of the PAC's contribution on the first period election, and the subscripts correspond to the candidate's status in the first period election. A contribution to the incumbent in the first period, by increasing the likelihood that a candidate wins the first period election, increases the likelihood that candidate will continue to be the incumbent after the second period election. $\Delta P$ is the increase in the likelihood that the recipient wins in 
period 1 , the term in square brackets is the likelihood that he or she runs and wins at time 2, and the term in parentheses is the expected difference in the period 2 roll-call voting behavior that results from having the recipient in office. ${ }^{10}$ Note the similarity between equations (7) and (8). If PAC contributions to incumbents and challengers have the same marginal effect on election outcomes (i.e., $\Delta P_{i}=\Delta P_{c}$ ), then the effect on the PAC's period 2 payoff of a contribution to the challenger in period 1 is exactly the opposite of the effect of giving to the incumbent in period 1. The symmetry in equations (7) and (8) is an extension of the observation made above that the effectiveness of the election-influencing channel does not depend on a candidate's absolute likelihood of winning, but rather depends only on the increment to that likelihood, $\Delta P$.

Derivation of the effect of the PAC's period 1 contribution on payoffs in periods 3 to $\infty$ follow precisely the same approach as that presented above. The only difference is that the future payoffs are increasingly discounted as the likelihood of the first period candidate remaining in office declines. It is straightforward to demonstrate that the infinite series simplifies into the second term in the equations below, giving the following sums of discounted payoffs for the PACs:

$$
\begin{aligned}
& U_{i}-U_{n}=\left(P+\Delta P_{i}\right) \Delta V_{i}+\frac{\Delta P_{i}\left(V_{i}-V_{c}\right)}{\delta(1-(1-R) P)}-C \\
& U_{c}-U_{n}=\left(1-P+\Delta P_{c}\right) \Delta V_{c}+\frac{\Delta P_{c}\left(V_{c}-V_{i}\right)}{\delta(1-(1-R) P)}-C
\end{aligned}
$$

The first term in equations (9) and (10) reflects the roll-call vote buying channel, the second term is the election-influencing channel, and the third term is the cost of the contribution to the PAC. In choosing the optimal contribution strategy in period 1, the PAC simply determines the sign on equations (9) and (10). If both are negative, the PAC does not contribute to either candidate. If one or both is positive, the PAC contributes to the incumbent (challenger) if the value of (9) is greater than (less than) the value of (10).

The comparative statics of (9) and (10) are simple, but illuminating. The more willing is a candidate to sell roll-call votes to the PAC (i.e., the larger is $\Delta V$ ) and the more likely is the candidate to win the election, the more attractive is a donation to that candidate via the roll-call vote buying channel. In terms of influencing elections, the ability of the PAC to affect the election outcome is an important factor, as is the difference in positions between the two candidates on

\footnotetext{
${ }^{10}$ It is interesting to note that equations (7) and (8) depend on $V_{i}$ and $V_{c}$ (the candidate types in the first period election), but do not depend on the expected policy stance of the challenger in the second period election. This outcome is a result of the assumption that neither $P$, the probability of winning, nor $R$, the retirement rate, depend on the identity of the winner of the first period election. Consequently, the second-period challenger is equally likely to gain office regardless of what contribution strategy is pursued in the first period.
} 
the PAC's issue, and also the likelihood that today's investment in a candidate will continue to pay off in the future. Therefore, the PAC's discount rate, the retirement rate, and the re-election rate of incumbents also help to determine the attractiveness of PAC donations. To the extent that challenger campaign spending is more productive in influencing the popular vote, contributions to challengers will be more attractive to PACs through this channel. As the marginal cost $C$ of raising funds increases, contributions to either candidate become less likely.

To obtain a better intuition for the results of the model, it is convenient to look at a special case where there are only three types of candidates: supporter, undecided, or opposed. Supporters always support the PAC's position, regardless of campaign contributions. Likewise, candidates who are opposed to the PAC always vote against the PAC's position, regardless of campaign contributions. Algebraically, $V_{s}=1, V_{o}=0$, and $\Delta V_{s}=\Delta V_{o}=0$. Undecided legislators, on the other hand, are influenced by PAC contributions. For simplicity, assume that the roll-call voting behavior of undecided challengers and undecided incumbents is affected equally by PAC contributions. ${ }^{11}$

Given the assumption that there are three types of candidates, there are nine possible permutations of elections. Rather than outline each possible scenario individually, the discussion is limited to highlighting the most noteworthy implications of the model: ${ }^{12}$

\section{1) The PAC will never contribute to an opposed candidate.}

An opposed candidate, by definition, will not change his or her vote in response to PAC contributions, so the vote-buying channel has no value. Furthermore, the PAC will never want to increase the likelihood that an opposed candidate wins election, so the election-influencing channel also has no value to the PAC.

\section{2) When two supporting candidates face one another, the PAC has no incentive to contribute.}

The PAC already has the roll-call support of both candidates, and from an election-influencing perspective is indifferent between which of the two candidates is victorious. ${ }^{13}$

\footnotetext{
${ }^{11}$ Snyder (1990) examines a more complicated case in which the equilibrium cost of vote-buying is a function of the likelihood of winning the election.

${ }^{12}$ No formal proofs are provided. The results follow directly from substitution into equations (9) and (10).

${ }^{13}$ In practice, however, there may be three reasons not incorporated into the model why this prediction of the model is violated. First, the PAC may prefer a more senior representative to a freshman, and thus may prefer to have the incumbent win. Second, to the extent that PAC contributions motivate supporters to take a more active role in introducing legislation and participating in committee activities [Hall and Wayman (1990)], contributions to the expected winner may have value to the PAC. Finally, the withdrawal of support for an incumbent who has previously been supported by the PAC may adversely affect the PAC's relationship with the candidate, inducing serial correlation between PAC donations across elections [Snyder (1992)].
} 
3) If the vote-buying channel is important enough, a PAC may be willing to contribute to an undecided candidate, even when the opponent is a supporter.

The PAC would unambiguously prefer to have the supporter in office, but conditional on the undecided candidate winning, the PAC would like to have supported that candidate in the hope of influencing the roll-call vote ex post. In the limit, when the PAC contribution has no effect on election outcomes, the PAC will only contribute to undecideds.

4) Whenever there are no undecided candidates in the race, whether a candidate is an incumbent or a challenger will not affect the contribution strategy of the PAC.

As mentioned earlier, the election-influencing channel is independent of the likelihood of winning. In fact, if campaign spending is more valuable to challengers, PACs would actually prefer to give contributions to challengers if election-influencing were the only goal of donations.

\section{Numerical Examples}

Numerical examples can help to further clarify the implications of the model. In constructing the numerical examples, the assumption of three candidate types is maintained for tractability, and the three types are furthermore assumed to be equally prevalent. The retirement rate is set at 0.086 , the average retirement rate from the U.S. House over the period 1984-1992. ${ }^{14}$ The PAC's discount factor is set at $0.90 .{ }^{15}$

Assume first that the incumbent has a 0.95 likelihood of victory, the average re-election rate in the House from 1984-1992. The high likelihood of victory has two offsetting effects on the relative importance of the election-influencing channel. Because the incumbent is likely to hold the office for many terms, any incremental change in the likelihood of victory today is compounded over a long period of time. On the other hand, it is less likely that the PAC contribution will be the determining factor in the election outcome, since the incumbent is heavily favored. The key ratio turns out to be $\Delta V / \Delta P$, the relative likelihood of affecting a roll-call vote position vs. influencing the election. Even if $\Delta V / \Delta P=25$, however, implying that a given PAC contribution is twenty-five times more likely to affect the candidate's roll-call vote than the election outcome, the election-influencing channel accounts for over $25 \%$ of the value of the PAC contribution. When $\Delta V / \Delta P=5$, that fraction rises to almost two-thirds.

In a district where the incumbent always has only a $60 \%$ chance of victory, the value of election-influencing is greatly reduced for a given ratio of $\Delta V / \Delta P$ since the incumbent is unlikely to hold office for many periods. For $\Delta V / \Delta P=5$, the election-influencing channel accounts for $27 \%$ of the total; for $\Delta V / \Delta P=25$, that channel accounts for only $7.5 \%$.

\footnotetext{
${ }^{14}$ This retirement rate includes deaths and resignations.

${ }^{15} \mathrm{~A}$ more detailed description of the process by which the numerical examples are generated is presented in an earlier version of the paper, available on request from the author.
} 
The type of elections in which the election-influencing motive is likely to be greatest are those elections that are tightly contested this year, but where the victor is likely to have an easier go of it the next time around. Examples of such elections are open-seat elections when there is a large incumbency advantage, or elections involving incumbents who are short-run trouble due to scandal, a particularly capable challenger, or an unusually large negative partisan swing. Such elections involve a high likelihood that the PAC contribution will affect the election outcome, but are also rewarded by a long expected period of service by the victor. In such races, over $90 \%$ of the contribution to PACs comes through election-influencing if $\Delta V / \Delta P=5$, while $21 \%$ of the total is via that channel if $\Delta V / \Delta P=25$.

\section{SECTION III: EMPIRICAL TESTS OF THE MODEL}

In applying the theoretical model to the data, the primary objective is to determine the relative importance of the roll-call vote-buying and electioninfluencing channels for actual PAC contributions. In this section, I propose two simple approaches for achieving that goal, focusing on the U.S. House.

The first approach is based on the fact that there must be some likelihood that the PAC contribution will influence an election outcome in order for the election-influencing channel to have any value to PACs. ${ }^{16}$ If one could isolate a set of incumbents who occupy extremely safe seats, then it is likely that virtually all of the PAC contributions to such candidates are designed to influence rollcall voting patterns. ${ }^{17}$ Furthermore, if one is willing to assume that the "price" charged for candidates per delivered roll-call vote favor is independent of the closeness of the election (as one would expect if there is a free market for favors), then the total value of the vote-buying channel is constant across races. ${ }^{18}$ Consequently, comparing the ratio of total PAC contributions to both candidates in lopsided and close races provides a crude means of determining the relative importance of the two PAC channels.

Table 1 presents a breakdown of PAC contributions in lopsided and close contests for a number of recent election years. Because the intention in defining lopsided races is to isolate those races where the PAC cannot reasonably think that their contribution will affect the election, I adopt a very strict definition of lopsided: races in which the incumbent's party garners $70 \%$ or more of the two-

\footnotetext{
${ }^{16}$ Although the election influenced need not be this year's election. By helping to build a large war chest, PAC contributions today might influence future elections.

${ }^{17}$ This claim is subject to two important caveats. First, incumbents in seats that are safe in general elections may face stiff competition in the primary. Second, contributions in lopsided races may be given with the intention of influencing future election outcomes, either directly or through future campaign spending or indirectly through the creation of a war chest.

${ }^{18}$ Trading roll-call votes for PAC contributions has both a benefit and a cost. The benefit is PAC contributions; the cost is alienating voters by voting against their preferred positions. Without knowing the relative slopes of the cost and benefit curves as a function of the closeness of the race, it is impossible to know whether politicians should charge a higher or lower price for roll-call favors as races become more hotly contested.
} 
TAble 1. PAC Contributions in Lopsided vs. Close Races

\begin{tabular}{lccccccc}
\hline & \multicolumn{3}{c}{ Lopsided races } & & \multicolumn{3}{c}{ Close races } \\
\cline { 2 - 3 } \cline { 7 - 8 } Year & Incumbent & Challenger & Total & & Incumbent & Challenger & Total \\
\hline 1986 & 149.1 & 0.6 & 149.7 & & 286.3 & 143.9 & 430.2 \\
1988 & 178.2 & 1.2 & 179.4 & & 364.8 & 164.5 & 529.3 \\
1990 & 169.4 & 0.3 & 169.7 & & 293.8 & 98.3 & 392.1 \\
1992 & 157.7 & 2.4 & 160.1 & & 343.9 & 97.4 & 441.3 \\
Average & 163.6 & 1.1 & 164.7 & & 322.2 & 126.0 & 448.2 \\
\hline
\end{tabular}

Notes: Lopsided races are defined as those House races in which the incumbent received $70 \%$ or greater of the two-party vote in the current election, and the current incumbent's party also received at least $70 \%$ of the two-party vote in the three preceding elections. PAC contributions in such elections are likely to be solely for vote-buying purposes. Close races are defined as those House races in which the victor obtains $55 \%$ or less of the two-party vote. PAC contributions to such races are likely to have the greatest fraction of election-influencing motive. All values in the table are per race, in 1990 dollars. Some lopsided races did not involve a major party challenger; a PAC contribution of zero is assigned to challengers in such races. Any lopsided race in which the incumbent did not accept any PAC contributions, or close race in which one or both of the candidates did not accept PAC contributions are omitted. Open-seat elections are excluded. Data compiled from America Votes (multiple issues) and Politics in America (multiple issues).

party vote in both the current election, and in the three preceding elections. ${ }^{19}$ Close races are defined as those races in which the winning candidate wins $55 \%$ or less of the two-party vote. Open-seat elections are excluded from the analysis.

As Table 1 demonstrates, lopsided races attract a substantial quantity of PAC contributions for incumbents. Across the four election years considered, incumbents who are virtually assured for victory nonetheless receive an average of $\$ 163,600$ a piece in PAC contributions. Not surprisingly, challengers in such races, who have no chance of victory, receive virtually no PAC support: only $\$ 1,100$ each. Close races differ from lopsided races in two ways. First, the total PAC contributions to such races are over $170 \%$ higher. Second, the increased PAC contributions are split relatively equally between challengers and incumbents. Challengers in close races receive almost as much as incumbents in lopsided races, despite the fact that these challengers win far below $50 \%$ of these close races. While an analysis of this type cannot definitely prove the importance of the election-influencing channel, at a minimum it is consistent with such a story. ${ }^{20}$

The second approach to determining the relative importance of the electioninfluencing channel relies on the differential predictions of the theoretical model for PAC contributions by candidate type in response to partisan swings. In years when the party is strong, incumbents are extremely unlikely to lose, implying that the vote-buying channel should be strong, but the election-influencing

\footnotetext{
${ }^{19}$ When redistricting occurs, the incumbent's share of the vote in the old district is used.

${ }^{20}$ An alternative explanation for the low level of contributions in lopsided races is that incumbents in such races do not seek out PAC contributions, i.e. PACs would give if asked, but are not asked by candidates to give.
} 
channel weak. In 1994, for instance, not a single Republican incumbent was defeated in a House general election. When the party is weak incumbents are much more likely to be at risk, reducing the vote-buying channel but making the election-influencing channel strong. For challengers, however, favorable partisan swing will have a positive impact on both PAC channels. Precisely the opposite story holds for unfavorable partisan swing. Thus, by comparing relative PAC support, both by party and incumbency status, it becomes possible to ascertain the relative importance of the two PAC channels.

Table 2 presents various ratios of PAC contributions per candidate for each election cycle. Except where noted, contributions from labor PACs, which go almost exclusively to Democrats, are excluded to avoid any distortion of the results as a consequence of the changing composition of labor and non-labor PACs over time. The rows of the table correspond to election cycles from 1980 to 1994. To clarify the relationships in the table, the next to last row contains simple averages of the values from those elections most favorable to Democrats (1982, 1986, 1988, 1990), while the bottom row presents averages for the elections least favorable to Democrats $(1980,1984,1992,1994)$. The discussion of the results focuses exclusively on these bottom two rows.

Column 1 reports the Democratic share of the House vote. Column 2 presents the ratio of donations to challengers of the two parties. Both election-influencing and roll-call voting channels that Democratic challengers should benefit from favorable partisan swing. This result is borne out strongly in the data: Democratic challengers receive $18 \%$ more non-labor PAC contributions than Republican challengers in years where partisan swing favors Democrats, but only $54 \%$ of the Republican totals when Democratic election hopes are low.

The comparison of incumbents of different parties in column 3 sheds more light on the relative magnitudes of the competing PAC motives since the election-influencing and roll-call vote-buying channels point in opposite directions. Interestingly, Democratic incumbents actually receive a greater fraction of the PAC contributions in years where partisan swing is against them, suggesting that the election-influencing channel predominates, at least at the margin where these changes are occurring. Not surprisingly, given that the two effects are offsetting for incumbents, the magnitude of the gap is much smaller for incumbents.

Columns 4-6 compare the relative level of contributions within a party. The roll-call vote-buying channel should respond similarly for incumbents and challengers of the same party. Any difference in the allocation of PAC contributions within a party should therefore reflect election-influencing motives. Column 4 (column 5) presents the data for non-labor (labor) PAC contributions to Democrats. Column 6 reflects non-labor PAC contributions to Republicans. Election-influence predicts that challengers should obtain a higher share of PAC contributions when partisan swing favors the party. That prediction is validated in all three columns, providing further evidence in favor of the election-influencing channel. 


\begin{tabular}{|c|c|c|c|c|c|c|}
\hline & & $\begin{array}{l}\text { ABLE 2. PARTISAN } \\
\text { ios of PAC Contrib }\end{array}$ & $\begin{array}{l}\text { WING AND THE ALLO } \\
\text { tions per Candidate }\end{array}$ & $\begin{array}{l}\text { ATION OF PAC CON } \\
\text { or Different Types o }\end{array}$ & $\begin{array}{l}\text { RIBUTIONS } \\
\text { Candidates }\end{array}$ & \\
\hline Year & $\begin{array}{l}\text { Democratic } \\
\text { Share of vote }\end{array}$ & $\begin{array}{c}(2) \\
\frac{\text { Democ. Chall. }}{\text { Repub. Chall. }} \\
\text { (non-labor PACs) }\end{array}$ & $\begin{array}{c}(3) \\
\frac{\text { Democ. Incum. }}{\text { Repub. Incum. }} \\
\text { (non-labor PACs) }\end{array}$ & $\begin{array}{c}(4) \\
\frac{\text { Democ. Incum. }}{\text { Democ. Chall. }} \\
\text { (non-labor PACs) }\end{array}$ & $\begin{array}{c}(5) \\
\frac{\text { Democ. Incum. }}{\text { Democ. Chall. }} \\
\text { (labor PACs only) }\end{array}$ & $\begin{array}{c}(6) \\
\frac{\text { Repub. Incum. }}{\text { Repub. Chall. }} \\
\text { (non-labor PACs) }\end{array}$ \\
\hline 1980 & 50.4 & 0.12 & 0.72 & 11.29 & 1.83 & 1.81 \\
\hline 1982 & 55.2 & 0.60 & 0.68 & 4.94 & 1.44 & 4.36 \\
\hline 1984 & 52.1 & 0.28 & 0.82 & 12.13 & 2.46 & 4.12 \\
\hline 1986 & 54.5 & 1.29 & 0.82 & 6.55 & 1.98 & 10.40 \\
\hline $\begin{array}{l}\text { Elections most } \\
\text { favorable to } \\
\text { Democrats }\end{array}$ & 54.0 & 1.18 & 0.84 & 8.82 & 2.16 & 11.52 \\
\hline $\begin{array}{l}\text { Elections most } \\
\text { favorable to } \\
\text { Republicans }\end{array}$ & 49.7 & 0.54 & 0.91 & 11.98 & 2.51 & 6.58 \\
\hline
\end{tabular}

Table 2. Partisan Swing and the Allocation of PAC Contributions

Ratios of PAC Contributions per Candidate for Different Types of Candidates 


\section{SECTION IV: CONCLUSIONS}

This paper develops a dynamic model of PAC contributions, allowing for both an election-influencing and a roll-call vote-buying motive. It is demonstrated that the relative importance of the election-influencing channel is easily underestimated in a static model. A one-time contribution to a strong supporter of the PAC's positions has the potential to alter the composition of Congress for as long as that elected official holds office. Given that the candidate supports the PAC's positions anyway, no further contributions are required to influence that person's roll-call votes. In contrast, PAC contributions made with the goal of affecting roll-call voting patterns are likely to operate on a quid-pro-quo basis, necessitating repeated contributions to the marginal congressman. Empirical tests of the model confirm the presence of both types of PAC motives, although the evidence suggests that the election-influencing motive is the dominant channel. PACs make much smaller contributions to incumbents in lopsided races where there is no chance of the contribution influencing the election outcome. Also, PAC contributions to incumbents tend to be highest when partisan swing is most squarely against the incumbent's party. While there is less of a chance the incumbent will be re-elected in such a case (reducing the value of the roll-call vote channel), there is a greater chance that the PAC's contribution will be pivotal in the election (increasing the election-influencing motive).

The empirical evidence presented in this paper is only a first step in testing the theoretical predictions of the model. Another approach to testing the model would focus on individual-level data rather than the aggregate data used in this paper. The most serious obstacle to achieving that objective is that PAC giving will be a function of the relative positions of the competing candidates on the issues of interest to the PAC. While roll-call votes, spatial voting models, and interest group ratings provide accurate measures of an incumbent's position on the issues, the corresponding measures are not generally available for challengers. That lack of available information makes further analysis more difficult, but certainly should not pose an impossible hurdle. For instance, one possible approach would be to examine only those campaigns in which both contestants already hold nationallevel elective office, i.e. cases where House members challenge an incumbent senator, or two House incumbents face one another as a result of redistricting.

\section{ACKNOWLEDGMENTS}

I would like to thank Steve Ansolabehere, Tim Groseclose, Robert Reed, and James Snyder for helpful discussions and comments, and the National Science Foundation for financial support.

STEVEN D. LEVITT

University of Chicago, Department of Economics

1126 East 59th Street, Chicago, IL 60637

and the American Bar Foundation

(c) Blackwell Publishers Ltd 1998.

Copyright $\odot$ 2000. All rights reserved. 


\section{REFERENCES}

Ansolabehere, S. and J. Snyder, 1996, Money, Elections, and Candidate Quality. Mimeo, M.I.T. Department of Political Science.

Austen-Smith, D., 1987, Interest Groups, Campaign Contributions, and Probabilistic Voting. Public Choice 54, 123-139.

Baron, D., 1989, Service-Induced Campaign Contributions and the Electoral Equilibrium. Quarterly Journal of Economics 104, 45-72.

Birnbaum, J. and A. Murray, 1987, Showdown at Gucci Gulch (Random House, New York).

Bronars, S. and J. Lott, 1994, Do Campaign Contributions Alter How Politicians Vote? Mimeo, Chicago Business School.

Chappell, H., 1982, Campaign Contributions and Congressional Voting: A Simultaneous Probit-Tobit Model. Review of Economics and Statistics 64, 77-83.

Clawson, D., 1992, Money Talks: Corporate PACs and Political Influence (Basic Books, New York).

Erikson, R. and T. Palfrey, 1993, The Spending Game: Money, Votes, and Incumbency in Congressional Elections. California Institute of Technology Working Paper.

Gelman, A. and G. King, 1990, Estimating Incumbency Advantage without Bias. American Journal of Political Science 34, 1142-1164.

Gopoian, D., 1984, What Makes PACs Tick? An Analysis of the Allocation Patterns of Economic Interest Groups. American Journal of Political Science 28, 259-281.

Green, D. and J. Krasno, 1988, Salvation for the Spendthrift Incumbent: Re-estimating the Effects of Campaign Spending in House Elections. American Journal of Political Science 32, 884-907.

Green, D. and J. Krasno, 1990, Rebuttal to Jacobson's "New Evidence for Old Arguments". American Journal of Political Science 34, 363-372.

Grenzke, J., 1989, PACs in the Congressional Supermarket: The Currency is Complex. American Journal of Political Science 33, 1-24.

Grier, K. and M. Munger, 1986, The Impact of Legislator Attributes on Interest Group Campaign Contributions. Journal of Politics 55, 615-643

Hall, R. L. and F. W. Wayman, 1990, Buying Time: Moneyed Interests and the Mobilization of Bias in Congressional Committees. American Political Science Review 84, 797-820.

Jacobson, G., 1980, Money in Congressional Elections (Yale University Press, New Haven).

Jacobson, G., 1985, Money and Votes Reconsidered: Congressional Elections, 1972-1982. Public Choice 47, 7-62.

Jacobson, G., 1990, The Effects of Campaign Spending in House Elections: New Evidence for Old Arguments. American Journal of Political Science 34, 334-362.

Levitt, S. D., 1994, Using Repeat Challengers to Estimate the Effects of Campaign Spending on Election Outcomes in the U.S. House. Journal of Political Economy 102, 777-798.

Levitt, S. D. and C. Wolfram, 1996, Decomposing the Sources of Incumbency Advantage in the U.S. House. Legislative Studies Quarterly 22, 45-60.

McCarty, N. and L. Rothenberg, 1994, Commitment and the Campaign Contribution Contract. Mimeo, University of Southern California.

Ornstein, N. J., T. E. Mann, and M. J. Malbin, 1994, Vital Statistics on Congress, 19931994 (Congressional Quarterly, Washington, DC).

Poole, K., T. Romer, and H. Rosenthal, 1987, The Revealed Preferences of Political Action Committees. American Economic Review 77, 298-302.

Sabato, L., 1985, PAC Power (Norton, New York).

Snyder, J., 1990, Campaign Contributions as Investments: The U.S. House of Representatives, 1980-1986. Journal of Political Economy 98, 1195-1227. 
Snyder, J., 1992, Long-Term Investing in Politicians, or Give Early, Give Often. Journal of Law and Economics 35, 15-44.

Sorauf, F., 1992, Inside Campaign Finance (Yale University Press, New Haven).

Stratmann, T., 1992, Are Contributors Rational? Untangling Strategies of Political Action Committees. Journal of Political Economy 100, 647-664. 